\title{
Efficient Stabilization of Na Storage Reversibility by Ti Integration into $\mathrm{O}^{\prime} 3$-Type $\mathrm{NaMnO}_{2}$
}

\author{
Takuro Sato, ${ }^{1}$ Kazuki Yoshikawa, ${ }^{2}$ Wenwen Zhao, ${ }^{2,3}$ Tokio Kobayashi, ${ }^{1}$ \\ Hongahally Basappa Rajendra $\mathbb{D}^{\mathbb{D}},{ }^{1}$ Masao Yonemura $\mathbb{D}^{4,5}$ and Naoaki Yabuuchi $\mathbb{D}^{1,3,6}$ \\ ${ }^{1}$ Department of Chemistry and Life Science, Yokohama National University, 79-5 Tokiwadai, Hodogaya-ku, Yokohama, \\ Kanagawa 240-8501, Japan \\ ${ }^{2}$ Department of Applied Chemistry, Tokyo Denki University, Adachi, Tokyo 120-8551, Japan \\ ${ }^{3}$ Elements Strategy Initiative for Catalysts and Batteries, Kyoto University, f1-30 Goryo-Ohara, Nishikyo-ku, Kyoto 615-8245, Japan \\ ${ }^{4}$ Institute of Materials Structure Science, High Energy Accelerator Research Organization, Tsukuba, Ibaraki 305-0801, Japan \\ ${ }^{5}$ Department of Materials Structure Science, Sokendai (The Graduate University for Advanced Studies), 203-1 Shirakata, Tokai, \\ Ibaraki 319-1106, Japan \\ ${ }^{6}$ Advanced Chemical Energy Research Center, Yokohama National University, 79-5 Tokiwadai, Hodogaya-ku, Yokohama, \\ Kanagawa 240-8501, Japan
}

Correspondence should be addressed to Naoaki Yabuuchi; yabuuchi-naoaki-pw@ynu.ac.jp

Received 3 February 2021; Accepted 7 May 2021; Published 26 May 2021

Copyright (C) 2021 Takuro Sato et al. Exclusive Licensee Beijing Institute of Technology Press. Distributed under a Creative Commons Attribution License (CC BY 4.0).

The development of an energy storage system with abundant elements is a key challenge for a sustainable society, and the interest of $\mathrm{Na}$ intercalation chemistry is extending throughout the research community. Herein, the impact of Ti integration into $\mathrm{NaMnO}_{2}$ in a binary system of $x \mathrm{NaMnO}_{2}-(1-x) \mathrm{TiO}_{2}(0.5 \leq x \leq 1)$ is systematically examined for rechargeable Na battery applications. Stoichiometric $\mathrm{NaMnO}_{2}$, which is classified as an in-plane distorted $\mathrm{O}^{\prime}$ 3-type layered structure, delivers a large initial discharge capacity of approximately $200 \mathrm{mAh} \mathrm{g}^{-1}$, but insufficient capacity retention is observed, most probably associated with dissolution of $\mathrm{Mn}$ ions on electrochemical cycles. Ti-substituted samples show highly improved electrode performance as electrode materials. However, the appearance of a sodium-deficient phase, $\mathrm{Na}_{4} \mathrm{Mn}_{4} \mathrm{Ti}_{5} \mathrm{O}_{18}$ with a tunnel-type structure, is observed for Ti-rich phases. Among the samples in this binary system, $\mathrm{Na}_{0.8} \mathrm{Mn}_{0.8} \mathrm{Ti}_{0.2} \mathrm{O}_{2}(x=0.8)$, which is a mixture of a partially Ti-substituted $\mathrm{O}^{\prime}$ 3-type layered oxide $\left(\mathrm{Na}_{0.88} \mathrm{Mn}_{0.88} \mathrm{Ti}_{0.12} \mathrm{O}_{2}\right)$ and tunnel-type $\mathrm{Na}_{4} \mathrm{Mn}_{4} \mathrm{Ti}_{5} \mathrm{O}_{18}$ as a minor phase elucidated by Rietveld analysis on both neutron and X-ray diffraction patterns, shows good electrode performance on the basis of energy density and cyclability. Both phases are electrochemically active as evidenced by in situ X-ray diffraction study, and the improvement of reversibility originates from the suppression of $\mathrm{Mn}$ dissolution on electrochemical cycles. From these results, the feasibility of $\mathrm{Mn}$-based electrode materials for high-energy rechargeable $\mathrm{Na}$ batteries made from only abundant elements is discussed in detail.

\section{Introduction}

Research interest of rechargeable sodium batteries is continuously growing due to the increasing demand for low-cost energy storage devices for stationary applications. During the past decade, considerable research efforts have been devoted to develop electrode materials for sodium batteries $[1,2]$. Particularly, research has been focused on the searching of advanced positive electrode materials. Among the various types of potential positive electrode materials, layered oxides and polyanionic compounds have drawn intensive attention [3-8]. As the most examined branches of positive electrode materials, layered-type transition metal oxides, $\mathrm{Na}_{x} M \mathrm{O}_{2}(M=3 \mathrm{~d}$ transition metals), with different layered stacking manners have been intensively examined due to the wider selection for tailoring layered structures and electrode performance [7-13]. From a practical perspective, the use of electrode materials made from Earth-abundant 
transition metal elements is preferable, and the oxides with $\mathrm{Fe}$ and $\mathrm{Mn}$ ions have been studied as strong candidates for sodium battery applications [14].

Among Mn-based oxides studied for sodium storage applications, $\mathrm{Na}_{0.44} \mathrm{MnO}_{2}\left(\mathrm{Na}_{4} \mathrm{Mn}_{9} \mathrm{O}_{18}\right)$ with a tunnel-type host structure [15] and $\mathrm{Na}_{0.7} \mathrm{MnO}_{2}$ with a P2-type layered structure [16] have been extensively studied. Herein, "P" denotes environment for $\mathrm{Na}$ ions, and $\mathrm{Na}$ ions are found at prismatic sites [17]. The number " 2 " corresponds to numbers of $\mathrm{MeO}_{2}$ slabs in a unit cell. Both oxides show promising electrode performance with excellent reversibility in $\mathrm{Na}$ cells. Nevertheless, both oxides are Na-deficient phases, and therefore, a small reversible capacity is obtained for a full cell configuration. To solve this problem, the use of a sacrificial salt, such as $\mathrm{Na}_{2} \mathrm{CO}_{3}$, has been proposed in literature [18]. However, available volumetric energy density is inevitably lowered by addition of sacrificial salts. Therefore, a stoichiometric layered material, $\mathrm{NaMnO}_{2}$ (or $\mathrm{Na}-$ rich compounds [19]), is more preferable for the full cell configuration. $\mathrm{NaMnO}_{2}$ has been studied as an electrode material in early 1980s [20]. $\mathrm{NaMnO}_{2}$ has two polymorphs, a low-temperature alpha phase with a monoclinic distorted O'3-type layered structure, and a high-temperature beta phase with an orthorhombic zigzag-type layered structure. Here, "O" denotes an octahedral environment for $\mathrm{Na}$ ions, and the prime symbol indicates the presence of in-plane distortion for $\mathrm{MeO}_{2}$ slabs [17]. Both phases consist of a cubic close-packed oxygen array, and therefore, intergrowth of both phases is experimentally observed [21]. Electrode performance of alpha- $\mathrm{NaMnO}_{2}$ was reexamined in 2011 [5], but reversibility is not acceptable for battery applications. In contrast, the high-temperature phase shows much improved electrode performance [21] when compared with the low-temperature phase. However, beta- $\mathrm{NaMnO}_{2}$ synthesized at high temperatures contains a large fraction of alpha$\mathrm{NaMnO}_{2}$ domains [21,22], and this fact probably originates from structural compatibility and similarity of formation energy in both phases. Therefore, to the best of our knowledge, successful synthesis of "phase-pure" beta- $\mathrm{NaMnO}_{2}$ without alpha domains is not found in the literature. Recently, stabilization of beta- $\mathrm{NaMnO}_{2}$ by Cu-substitution has been reported and $\mathrm{NaCu}_{0.1} \mathrm{Mn}_{0.9} \mathrm{O}_{2}$ crystallizes into the beta phase with less alpha domains [23, 24].

In this article, significant improvement of electrode performance of $\mathrm{O} 3 \mathrm{NaMnO}_{2}$ is described through a different and simple methodology without less abundant elements, i.e., Ti substitution for $\mathrm{Mn}$ ions. A binary system of $x \mathrm{NaMnO}_{2}-(1-x) \mathrm{TiO}_{2}(1 \leq x \leq 0.5)$ is systematically examined and tested as electrode materials in $\mathrm{Na}$ cells. Our previous work has demonstrated that $\mathrm{Na}$-deficient layered phases are successfully obtained in a binary system of $\mathrm{NaCrO}_{2}-\mathrm{TiO}_{2}$, and highly improved electrode performance is realized for solid solution samples in this binary system [25]. A solubility limit of $\mathrm{TiO}_{2}$ in $\mathrm{NaCrO}_{2}$ without the destruction of layered structures reaches approximately $40 \%$. In the case of $\mathrm{NaMnO}_{2}$, a much narrower solubility limit of $\mathrm{TiO}_{2}$ is found because of higher phase stability of $\mathrm{Na}_{4} \mathrm{Mn}_{4} \mathrm{Ti}_{5} \mathrm{O}_{18}$ with a tunnel-type structure [26]. Nevertheless, Ti-substituted and $\mathrm{Na}$-deficient $\mathrm{O}^{\prime} 3$-type layered phases are successfully obtained, and the samples show promising electrode performance as positive electrode materials for rechargeable $\mathrm{Na}$ batteries. From these results, the possibility of the development of high-performance batteries made from only Earth-abundant elements is discussed in detail.

\section{Experimental}

2.1. Synthesis of Materials. The binary system of $x$ $\mathrm{NaMnO}_{2}-(1-x) \mathrm{TiO}_{2}(0.5 \leq x \leq 1)$ with different chemical compositions was synthesized through a solid-state calcination method. Starting materials consisting of $\mathrm{Na}_{2} \mathrm{CO}_{3}$ (99.5\%; Wako Pure Chemical Industries), $\mathrm{Mn}_{2} \mathrm{O}_{3}$, and anatase-type $\mathrm{TiO}_{2}$ (98.5\%, Wako Pure Chemical Industries) were thoroughly mixed by ball milling. $\mathrm{Mn}_{2} \mathrm{O}_{3}$ was obtained from $\mathrm{MnCO}_{3}$ (Kishida Chemical) by heating at $850^{\circ} \mathrm{C}$ for $12 \mathrm{~h}$ in air. Mixtures after milling were pressed into pellets and calcined at $800(0.9 \leq x \leq 1)$ or $1000^{\circ} \mathrm{C}(0.5 \leq x \leq 0.8)$ in $\mathrm{Ar}$ for $12 \mathrm{~h}$ in a tube furnace. To enhance the electrode performance, the sample was thoroughly mixed with acetylene black (sample : acetylene black $=90: 10 \mathrm{wt} \%$ ) by using a planetary ball mill (Pulverisette 7, Fritsch) at $300 \mathrm{rpm}$ for $6 \mathrm{~h}$ with a zirconia pot and balls. Thus, obtained carbon composited samples were handled in an Ar-filled glove box to avoid contact to moist air.

2.2. Characterization of Materials. Crystal structures of the samples were examined by using an X-ray diffractometer (XRD) equipped with a high-speed position-sensitive detector (D2 Phaser, Bruker). Nonmonochromatized $\mathrm{Cu} \mathrm{K} \alpha$ radiation was utilized as an X-ray source with a nickel filter. The morphological features of the samples were observed using a scanning electron microscope (JEOL, JCM-6000). Synchrotron XRD data were collected at the beamline BL16B2 in SPring-8 synchrotron facility in Japan [27]. The measurement was conducted using an automatic powder diffraction system for Debye-Scherrer geometry using a capillary sample. The wavelength of X-ray was calibrated to be $0.5003 \AA$ with $\mathrm{CeO}_{2}$ reference. Rietveld refinement was carried out using RIETAN-FP software [28]. A neutron diffraction pattern was collected at BL09 (SPICA) in the Material and Life Science Facility (MLF) at the Japan Proton Accelerator Research Complex (J-PARC) [29]. Structural analysis of the neutron diffraction pattern was carried out using Z-Rietveld $[30,31]$.

The electrode performance of the samples was examined in Na cells. The composite positive electrodes, consisting of $76.5 \mathrm{wt} \%$ the carbon composited sample, $13.5 \mathrm{wt} \%$ acetylene black, and $10 \mathrm{wt} \%$ poly(vinylidene fluoride), pasted on aluminum foil as a current collector were tested. The electrodes were dried at $120^{\circ} \mathrm{C}$ in a vacuum. Metallic sodium foil was used as a negative electrode. The electrolyte solution used was $1.0 \mathrm{~mol} \mathrm{dm}^{-3} \mathrm{NaPF}_{6}$ dissolved in propylene carbonate (Battery grade, Kishida Chemical). A glass filter (GB-100R, Advantec) was used as separator. Two-electrode electrochemical cells (TJ-AC, Tomcell Japan) were assembled in the Ar-filled glove box and cycled at a rate of $10 \mathrm{~mA} \mathrm{~g}^{-1}$ at room temperature. The rate capability of the samples was 

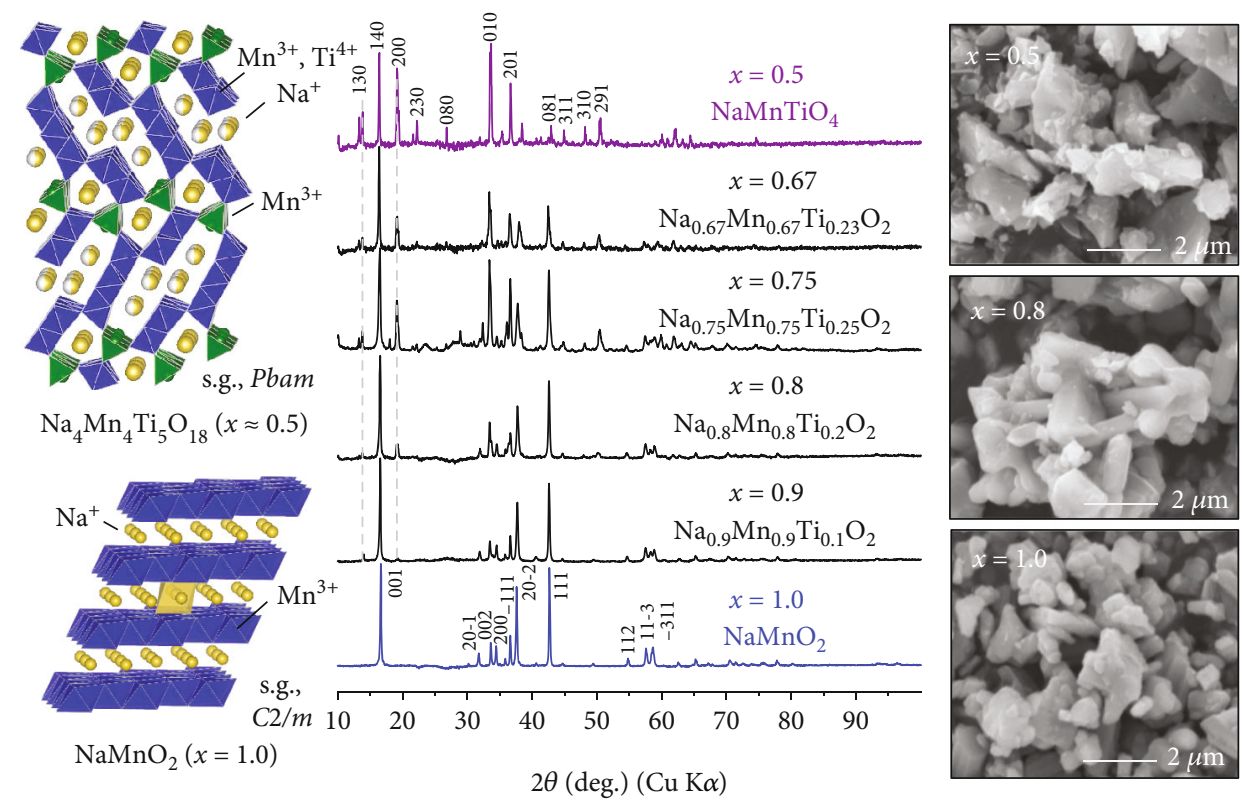

FIGURE 1: XRD patterns of the binary system of $x \mathrm{NaMnO}_{2}-(1-x) \mathrm{TiO}_{2}(0.5 \leq x \leq 1)$. Schematic illustrations of crystal structures drawn using the program VESTA [49] and SEM images of the samples are also shown.

also evaluated in $\mathrm{Na}$ cells. The cells were charged at the same current density of $20 \mathrm{~mA} \mathrm{~g}^{-1}$ to $4.5 \mathrm{~V} v s$. Na and then discharged at various rates $\left(20-1280 \mathrm{~mA} \mathrm{~g}^{-1}\right)$ to $1.2 \mathrm{~V}$. Impedance measurement was conducted by using a potentiostat with a frequency response analyzer (SP-200, Bio-Logic) at $10 \mathrm{mV}$ amplitude.

Hard X-ray absorption spectroscopy (XAS) at the Mn $\mathrm{K}$-edge was performed at beamline BL-9C of the Photon Factory Synchrotron Source in Japan. Hard XAS spectra were collected with a silicon monochromator in transmission mode. The intensity of incident and transmitted X-rays was measured using an ionization chamber at room temperature. Composite electrode samples were prepared using the twoelectrode cells at a rate of $10 \mathrm{~mA} \mathrm{~g}^{-1}$. The composite electrodes were rinsed with dimethyl carbonate and sealed in a water-resistant polymer film in the Ar-filled glove box. Normalization of the XAS spectra was carried out using the program code IFEFFIT [32]. The postedge background was determined using a cubic spline procedure.

In situ XRD patterns were obtained using an electrochemical cell equipped with a Be window and XRD diffractometer (Bruker, D8 Advance). Slurry was pasted on thin $\mathrm{Al}$ foil $(5 \mu \mathrm{m})$ and used as a composite electrode for in situ measurement. The cell was charged at a rate of $5 \mathrm{~mA} \mathrm{~g}^{-1}$, and the XRD data were collected for a second charge process.

\section{Results and Discussion}

3.1. Synthesis and Structural Characterization of Ti-Substituted $\mathrm{NaMnO}_{2}$. Figure 1 shows XRD patterns of a binary system for $x \mathrm{NaMnO}_{2}-(1-x) \mathrm{TiO}_{2}(0.5 \leq x \leq 1)$ prepared by a solidstate calcination method. Observed diffraction lines for $\mathrm{NaMnO}_{2}(x=1.0)$ are successfully indexed to an $\mathrm{O}^{\prime} 3$-type layered structure with a space group of $C 2 / \mathrm{m}$. The refined lat- tice parameters for $\mathrm{NaMnO}_{2}$ are $a=5.668 \AA, b=2.859$ $\AA, \quad c=5.800 \AA$, and $\beta=113.18^{\circ}$, which is consistent with the reported data in literature [5]. Generally, in-plane distortion of $\mathrm{NaMnO}_{2}$ originates from the Jahn-Teller effect of $\mathrm{Mn}^{3+}$ ion $\left(\mathrm{t}_{2 \mathrm{~g}}{ }^{3} \mathrm{e}_{\mathrm{g}}{ }^{2}\right)$, and a ratio of $a / b$ values (1.98) is indicative of the degree of in-plane distortion for layered materials. As Ti fractions increase, significant changes on XRD patterns are noted. A nearly single phase of $\mathrm{Na}_{4} \mathrm{Mn}_{4} \mathrm{Ti}_{5} \mathrm{O}_{18}$ is also obtained at $x=0.5$. This phase is essentially isostructural with $\mathrm{Na}_{0.44} \mathrm{MnO}_{2}$ [15], and a framework structure consists of $\mathrm{Mn}(\mathrm{Ti}) \mathrm{O}_{6}$ octahedra and $\mathrm{MnO}_{5}$ square pyramids, forming a tunnel-type structure as shown in Figure 1 [26]. Na ions are found at three distinct crystallographic sites in the tunneltype framework structure. Similar phases for $\mathrm{Na}-\mathrm{Mn}-\mathrm{Ti}$ ternary oxides with the tunnel-type structure have been also reported in literature $[33,34]$. Note that the presence of this phase is evidenced even for the sample of $x=0.9$ from the XRD patterns, and the Mn-rich layered oxide coexists with the Tirich tunnel-structured oxide for the samples of $0.5<x \leq 0.9$. The presence of the Ti-rich oxide and phase segregation is also clearly evidenced from elemental distribution maps shown in Supporting Figure S1. Nevertheless, a small amount of Ti ions is also found in the Mn-rich region as a major phase from the elemental maps. This fact suggests that $\mathrm{Ti}$ ions are partially incorporated in the layered phase, forming $\mathrm{Na}_{1-x} \mathrm{Ti}_{x} \mathrm{Mn}_{1-x} \mathrm{O}_{2}$ with the layered structure. Moreover, a detailed structural analysis by the Rietveld analysis also supports this hypothesis and is further discussed in the later section.

Particle morphology of these samples observed by SEM is also shown in Figure $1 . \mathrm{NaMnO}_{2}$ without Ti substitution consists of agglomerated particles with nonuniform sizes $(0.3-1.0 \mu \mathrm{m})$. The Ti-substituted sample, $x=0.8$, has similar particle morphology with the nonsubstituted sample, but a larger particle size with smooth surface is noted. The 
difference probably originates from the fact that higher synthesis temperature was used for the Ti-substituted sample. Moreover, for $\mathrm{Na}_{0.5} \mathrm{Mn}_{0.5} \mathrm{Ti}_{0.5} \mathrm{O}_{2}$, densification of the pellet was observed after calcination. In addition to relatively large micrometer-sized particles, tiny particles are also found, which are formed when the pellet was mechanically crushed into powder form.

Figures 2(a) and 2(b) show a result of Rietveld refinement on neutron diffraction (ND) and synchrotron XRD patterns of the sample, $x=0.8$. Refined structural parameters are listed in Supporting Tables S1 and S2. Because similar lattice parameters are noted for the second phase for the all samples of $0.5 \leq x \leq 0.9$ in Figure 1 , the formation of $\mathrm{Na}_{4} \mathrm{Mn}_{4} \mathrm{Ti}_{5} \mathrm{O}_{18}$ with the tunnel-type structure as the second phase is hypothesized. Structural analysis reveals that nearly $20 \%$ (mass percent) of the second phase is present, from which a Ti content of the main phase is estimated and calculated (also see Figure 2(c)). On the basis of this hypothesis, a chemical composition of the major phase is estimated to be $\mathrm{Na}_{0.88} \mathrm{Mn}_{0.88} \mathrm{Ti}_{0.12} \mathrm{O}_{2}$ with the $\mathrm{O}^{\prime} 3$-type layered structure. The difference in fractions of $\mathrm{Ti}$ contents for the layered and tunnel structures is also consistent with the finding of elemental mapping for $\mathrm{Ti}$ distributions (Supporting Figure S1). Moreover, the consistent results are also noted for both the SXRD and ND patterns with this two-phase model. Such nonstoichiometric phase segregation has also been discussed in other Fe/Mn-based layered materials [35]. Successful substitution by $\mathrm{Ti}$ ions is also supported from a change in lattice parameters for the major phase. Lattice parameters of the major layered phase are calculated to be $a=5.599 \AA, b=2.860 \AA, c=5.821 \AA$, and $\beta=112.38^{\circ}$ as shown in Supporting Tables S1 and S2. The $a / b$ ratio (1.958) is decreased compared with the nonsubstituted sample mentioned above and close to the ideal value of $\sqrt{ } 3$ without in-plane distortion. This fact indicates that Jahn-Teller active $\mathrm{Mn}^{3+}$ ions are partly and successfully replaced by Jahn-Teller inactive $\mathrm{Ti}^{4+}$ ions without valence electrons. From the refined result for the neutron diffraction pattern, Bragg diffraction lines with small $d$-values $(\sim 0.5 \AA)$ are nicely refined with the two-phase model. Additionally, large isotropic displacement parameters are found for the sodium sites by Rietveld analysis on both neutron and X-ray diffraction data, which indicates that vacant sites are formed at sodium sites, leading to facilitating self-diffusion of $\mathrm{Na}$ ions [36].

3.2. Electrode Performance of Ti-Substituted $\mathrm{NaMnO}_{2}$. The influence of Ti substitution on the electrochemical properties of the binary system of $x \mathrm{NaMnO}_{2}-(1-x) \mathrm{TiO}_{2}(0.5 \leq x \leq 1)$ was examined in $\mathrm{Na}$ cells, and galvanostatic charge/discharge curves of the carbon composited samples are shown in Figure 3. Note that the electrode performance on this binary system is significantly increased by the preparation of carbon composited samples. For comparison, the electrode performance of "as-prepared" $\mathrm{NaMnO}_{2}$ is shown in Supporting Figure S2. Large irreversible capacity for the initial cycle (approximately $90 \mathrm{~mA} \mathrm{~h}^{-1}$ ) and large polarization are observed. Large irreversible capacity is drastically reduced (approximately $30 \mathrm{~mA} \mathrm{~h}^{-1}$ ) for the carbon composite

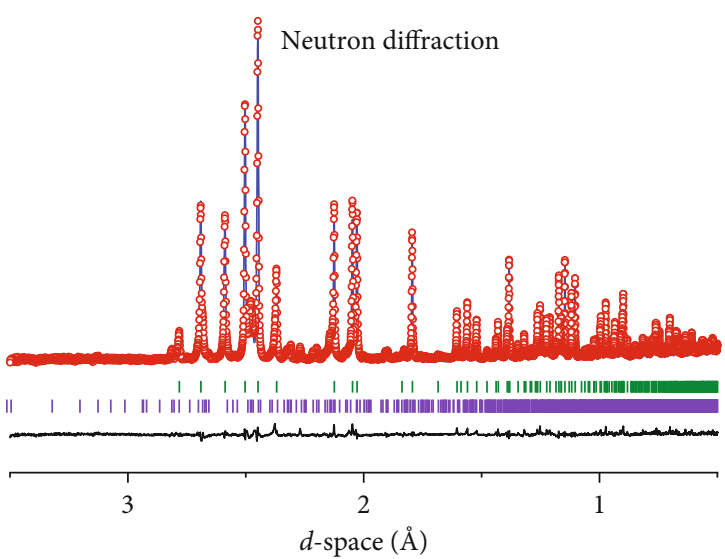

(a)

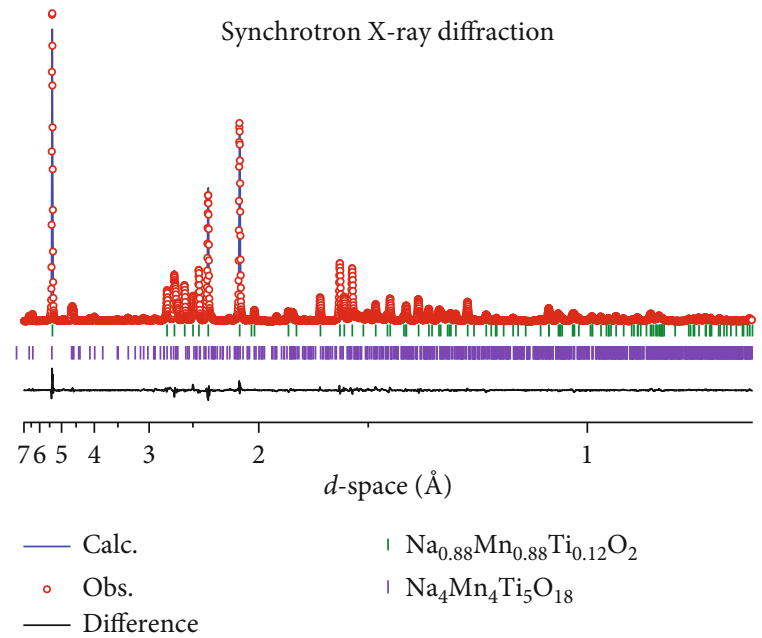

(b)

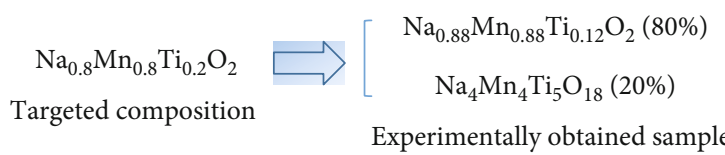

(c)

FIGURE 2: Results of Rietveld analysis on (a) synchrotron X-ray and (b) neutron diffraction patterns of the sample of $x=0.8$. A major phase crystallizes into the in-plane distorted layered structure, and the presence of a minor phase with the tunnel-type structure is also found. Refined structural parameters obtained by the Rietveld method are summarized in Supporting Tables S1 and S2. A scheme for the process of phase segregation and two-phase formation is also shown in (c).

sample, and initial discharge capacity reaches nearly $200 \mathrm{mAhg}^{-1}$. For the carbon composite sample, less agglomeration for secondary particles is noted from SEM images in Supporting Figure S2. Reduction of secondary particle sizes and uniform integration with nanosized carbon effectively improves the electrode performance of $\mathrm{NaMnO}_{2}$. Nevertheless, a reversible capacity of $35 \mathrm{~mA} \mathrm{~h} \mathrm{~g}^{-1}$ is lost during initial 10 cycles. It is noted that a browncolored separator is found after 10 cycles in a $\mathrm{Na}$ cell as shown in Figure 3(b), indicating that reduction of the reversible capacity partly originates from dissolution of $\mathrm{Mn}$ 


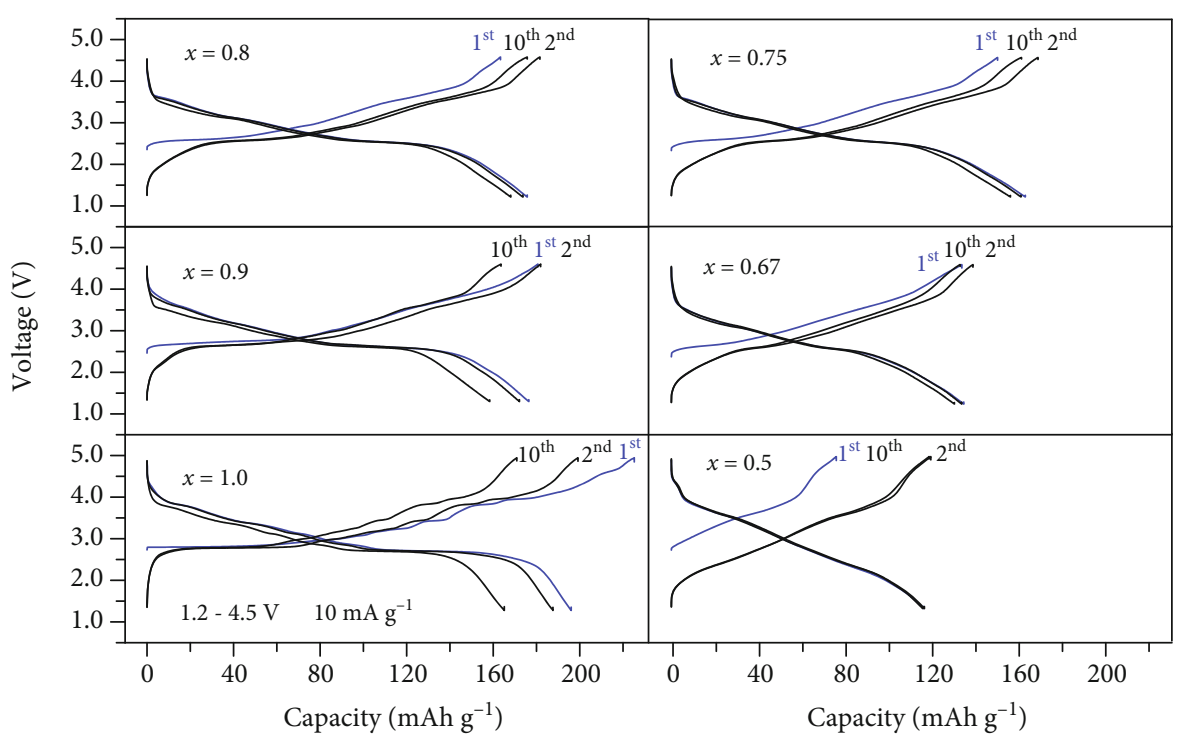

(a)

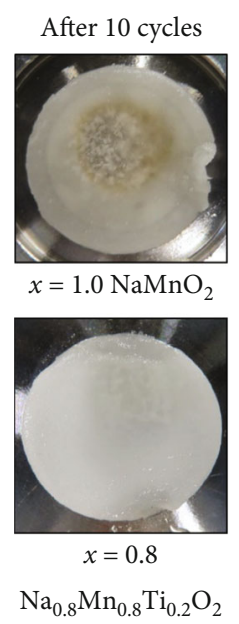

(b)

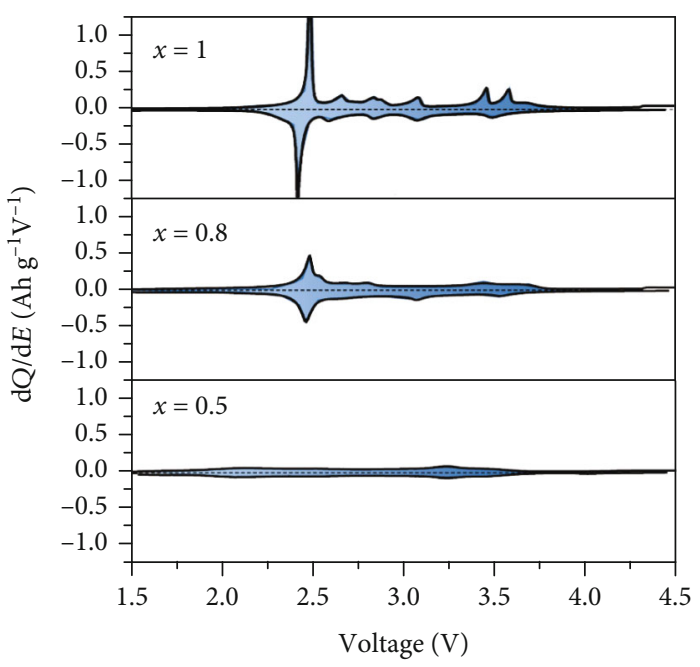

(c)

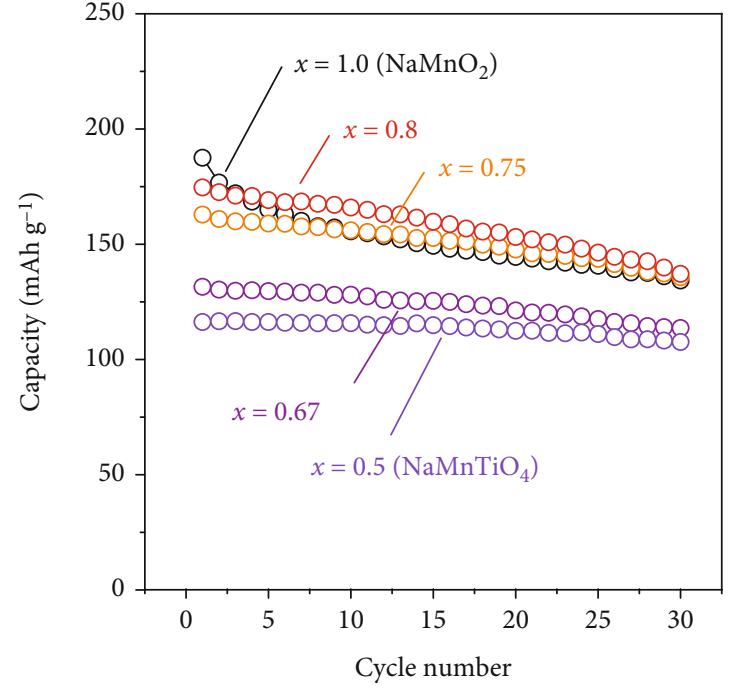

(d)

Figure 3: (a) Charge/discharge profiles of the binary system of $x \mathrm{NaMnO}_{2}-(1-x) \mathrm{TiO}_{2}(0.5 \leq x \leq 1)$ at a current density of $10 \mathrm{mAg} \mathrm{g}^{-1}$. (b) Separator of Na cells cycled with the samples of $x=1.0$ and 0.8 . (c) $\mathrm{d} Q / \mathrm{d} E$ differential curves obtained from (a) and (d) capacity retention of the binary phase.

ions into the electrolyte solution. This observation is also consistent with a recent theoretical study, and it is proposed that the presence of proton accelerates $\mathrm{Mn}$ migration in the crystal lattice, leading to $\mathrm{Mn}$ dissolution into electrolyte [37].

For $\mathrm{NaMnO}_{2}$, stepwise charge/discharge profiles are observed, which suggests that complicated and multiple phase transitions with a two-phase reaction are involved during cycling, probably associated with charge, spin, and orbital ordering on desodiation [38]. The nature of biphasic reaction is also clearly observed in $\mathrm{dQ} / \mathrm{d} E$ differential curves in Figure 3(c). In the case of Ti-substituted samples, obvious changes in voltage profiles are observed. As $\mathrm{Ti}$ contents increase, stepwise profiles are lost, and instead, S-shaped profiles are more pronounced, indicating that single-phase reac- tion proceeds in the entire range. For the Ti-rich sample, $x=0.5, \mathrm{NaMnTiO}_{4}$, a sloping voltage profile without voltage plateaus is observed, and no peak is found in $\mathrm{d} Q / \mathrm{d} E$ curves. Indeed, $\mathrm{Na}_{0.44} \mathrm{Mn}_{0.44} \mathrm{Ti}_{0.56} \mathrm{O}_{2}$, which has a similar chemical composition with $x=0.5$ shows a single-phase reaction revealed by in situ XRD study on electrochemical cycles [39]. $\mathrm{NaMnTiO}_{4}$ shows excellent capacity retention but an available reversible capacity is reduced to $120 \mathrm{mAhg}^{-1}$. Moreover, the initial charge capacity is quite small compared with the initial discharge capacity associated with the formation of the Na-deficient phase.

Among the tested sample in this binary system, the sample of $x=0.8, \mathrm{Na}_{0.8} \mathrm{Mn}_{0.8} \mathrm{Ti}_{0.2} \mathrm{O}_{2}$, shows superior electrode performance. A large initial discharge capacity reaches around $175 \mathrm{mAhg}^{-1}$, which is comparable to that of 
$\mathrm{NaMnO}_{2}$. Estimated energy density reaches $460 \mathrm{Wh} \mathrm{kg}^{-1} v s$. metallic Na. Moreover, capacity retention as electrode materials is significantly improved by Ti substitution. Indeed, no change in color of the separator is observed after 10 cycles as shown in Figure 3(b), and this observation clearly indicates that suppression of $\mathrm{Mn}$ dissolution is responsible for the improvement of cyclability. A voltage profile is also influenced by $\mathrm{Ti}$ substitution, and less pronounced voltage plateaus are observed in $\mathrm{d} Q / \mathrm{d} E$ curves (Figure 3(c)). These facts, including the results of structural analysis, conclude the successful synthesis of Ti-substituted $\mathrm{O}^{\prime} 3$ type manganese-based layered oxide. However, an initial charge capacity is slightly smaller than that of the initial discharge capacity associated with the formation of the $\mathrm{Na}$ deficient phase. Nevertheless, the concentration of $\mathrm{Na}$ deficient sites is relatively small compared with P2-type $\mathrm{Na}_{0.7} \mathrm{MnO}_{2}$ and $\mathrm{NaMnTiO}_{4}$, and therefore, for the sample of $x=0.8$, a sacrifice in energy density for the full cell configuration would be expected to be limited and small.

The impact of Ti substitution for Mn ions on electrode performance is further examined in $\mathrm{Na}$ cells. Quasi-opencircuit voltages (QOCV) for the samples of $x=1.0$ and 0.8 were measured by galvanostatic intermittent titration technique (GITT) as shown in Figure 4(a). Although polarization upon charging below $3.5 \mathrm{~V}$ is relatively small $(\sim 20 \mathrm{mV})$ for the sample of $x=1.0, \mathrm{NaMnO}_{2}$, the polarization is increased to $>100 \mathrm{mV}$ when charged above $3.5 \mathrm{~V}$. On the other hand, the sample of $x=0.8, \mathrm{Na}_{0.8} \mathrm{Mn}_{0.8} \mathrm{Ti}_{0.2} \mathrm{O}_{2}$, shows much smaller polarization than that of $x=1.0$, especially at the high-voltage region $(>3.5 \mathrm{~V})$. The reduction of polarization is further supported by impedance measurement as shown in Supporting Figure S3. The rate capability of both samples is also compared in Figure 4(b). Larger discharge capacities are observed for the nonsubstituted sample at slower rates. However, a clear difference in rate capability is evidenced for both samples as increase in current density. For the Ti-substituted sample, a relatively large discharge capacity of approximately $140 \mathrm{~mA} \mathrm{~h} \mathrm{~g}^{-1}$ is obtained even at $1280 \mathrm{~mA} \mathrm{~g}^{-1}$, corresponding to $80 \%$ of the discharge capacity at $20 \mathrm{~mA} \mathrm{~h} \mathrm{~g}^{-1}$. The reduction of polarization and improvement of rate capability are realized by $\mathrm{Ti}$ substitution. In general, the substitution of $\mathrm{Ti}^{4+}$ ions, which have no valence electron, for $\mathrm{Mn}^{3+}$ ions, is expected to result in reduction of electronic conductivity, but chemical stability is effectively improved by $\mathrm{Ti}$ substitution, and thus, dissolution of $\mathrm{Mn}$ ions into electrolyte solution is suppressed [40]. From these results, it is hypothesized that dissolution of $\mathrm{Mn}$ ions for the nonsubstituted sample results in gradual loss of electrical contact on electrochemical cycles, leading to the increase in the polarization as electrode materials.

The feasibility of the Ti-substituted sample as positive electrode materials is further examined in Na cells. Although the Ti-substituted sample shows much improved capacity retention compared with the non-substituted sample (Figure 3(d)), further improvement is required to use this material for practical applications. Therefore, the cut-off voltage for charge was reduced from $4.5 \mathrm{~V}$ to $4.2 \mathrm{~V}$ to avoid possible side reactions during high-voltage exposure, and voltage holding at $4.2 \mathrm{~V}$ after constant current charge was applied. When cut-off voltage is reduced to $4.2 \mathrm{~V}$, a much improved capacity retention is achieved as shown in Figure 4(c) even though an initial discharge capacity is inevitably reduced to $170 \mathrm{~mA} \mathrm{~h} \mathrm{~g}^{-1}$. In addition, capacity retention is further improved by voltage holding at $4.2 \mathrm{~V}$. An initial charge capacity reaches $185 \mathrm{~mA} \mathrm{~h} \mathrm{~g}^{-1}$, which is almost the same capacity with an initial discharge capacity. The problem of the Na-deficient phase, i.e., a small initial charge capacity, is less pronounced by using voltage holding at $4.2 \mathrm{~V}$. Charge/discharge curves of the Ti-substituted sample without voltage holding is shown in Supporting Figure S4. Approximately $90 \%$ of the reversible capacity is retained after 30 cycles at a rate of $20 \mathrm{~mA} \mathrm{~g}^{-1}$. A result of an accelerated cycle test at a rate of $50 \mathrm{~mA} \mathrm{~g}^{-1}$ is also shown in Figure $4(\mathrm{~d})$, and voltage holding at $4.2 \mathrm{~V}$ on charge was used in the cycle test. The Ti-substituted sample shows good capacity retention, and $85 \%$ of the reversible capacity is retained even after the 100-cycle test.

3.3. Sodiation/Desodiation Mechanisms of $\mathrm{Na}_{y} \mathrm{Mn}_{0.8} \mathrm{Ti}_{0.2} \mathrm{O}_{2}$. Reaction mechanisms of the sample of $x=0.8$ has been further examined by ex situ X-ray absorption (XAS) spectroscopy and in situ XRD study. Figure 5(a) shows that Mn K-edge XAS spectra continuously shift towards a higher energy region after charge to $4.2 \mathrm{~V}$, and an opposite trend is noted on discharge. The energy position shifts back to the original position after being discharged to $1.2 \mathrm{~V}$. From the energy position changes observed in XAS spectra, it is concluded that one electron redox of $\mathrm{Mn}$ ions, $\mathrm{Mn}^{3+} / \mathrm{Mn}^{4+}$, is effectively utilized in this system and this process is highly reversible. High reversibility of cationic redox reaction is achieved for $\mathrm{Na}_{0.8} \mathrm{Mn}_{0.8} \mathrm{Ti}_{0.2} \mathrm{O}_{2}$. It is also anticipated that the use of anionic redox reaction [41], coupled with these cationic redox, would further increase the reversible capacity and energy density of positive electrode materials by designing $\mathrm{Na}$-excess Mn-based oxides [42, 43].

To further examine the origin of good electrochemical reversibility for $\mathrm{Na}_{0.8} \mathrm{Mn}_{0.8} \mathrm{Ti}_{0.2} \mathrm{O}_{2}$, in situ XRD patterns of the sample on the electrochemical cycle have been collected as shown in Figure 5(b). For a fully discharged phase, a major phase is assigned into the $\mathrm{O}^{\prime} 3$-type layered phase (denoted as $\mathrm{O}^{\prime} 3 \mathrm{I}$ phase in Figures 5(b) and 6), and the presence of the oxide with the tunnel-type structure is also noted. On charge, the phase transition is clearly observed. The 20-2 diffraction line for the $\mathrm{O}^{\prime} 3 \mathrm{I}$ phase at 37.9 degrees in 2 theta is weakened, and new peak appears at 39.0 degrees. Similarly, new peaks are observed at 16.1 and 32.5 degrees, and these peaks are assigned as 001 and 002 diffraction lines for the monoclinic layered structure. This phase is observed in $0.62 \leq y \leq 0.82$ in $\mathrm{Na}_{y} \mathrm{Mn}_{0.8} \mathrm{Ti}_{0.2} \mathrm{O}_{2}$ and denoted as the $\mathrm{O}^{\prime} 3$ II phase in Figure 5(b). A two-phase coexistence of the $\mathrm{O}^{\prime} 3 \mathrm{I}$ and II phases is noted in the region of $0.86<y \leq 0.72$. The interlayer distance increases from 5.38 to $5.51 \AA$ for the $\mathrm{O}^{\prime} 3$ II phase. On further charge, the peak intensity of the $\mathrm{O}^{\prime} 3$ II phase is less intensified, and instead, the peak at 41.7 degrees appears. This phase is also assigned to be the $\mathrm{O}^{\prime} 3$-type phase (denoted as the $\mathrm{O}^{\prime} 3$ III phase), but the distortion of the crystal lattice ( $a / b$ ratio and $\beta$ angle for the monoclinic lattice) associated 

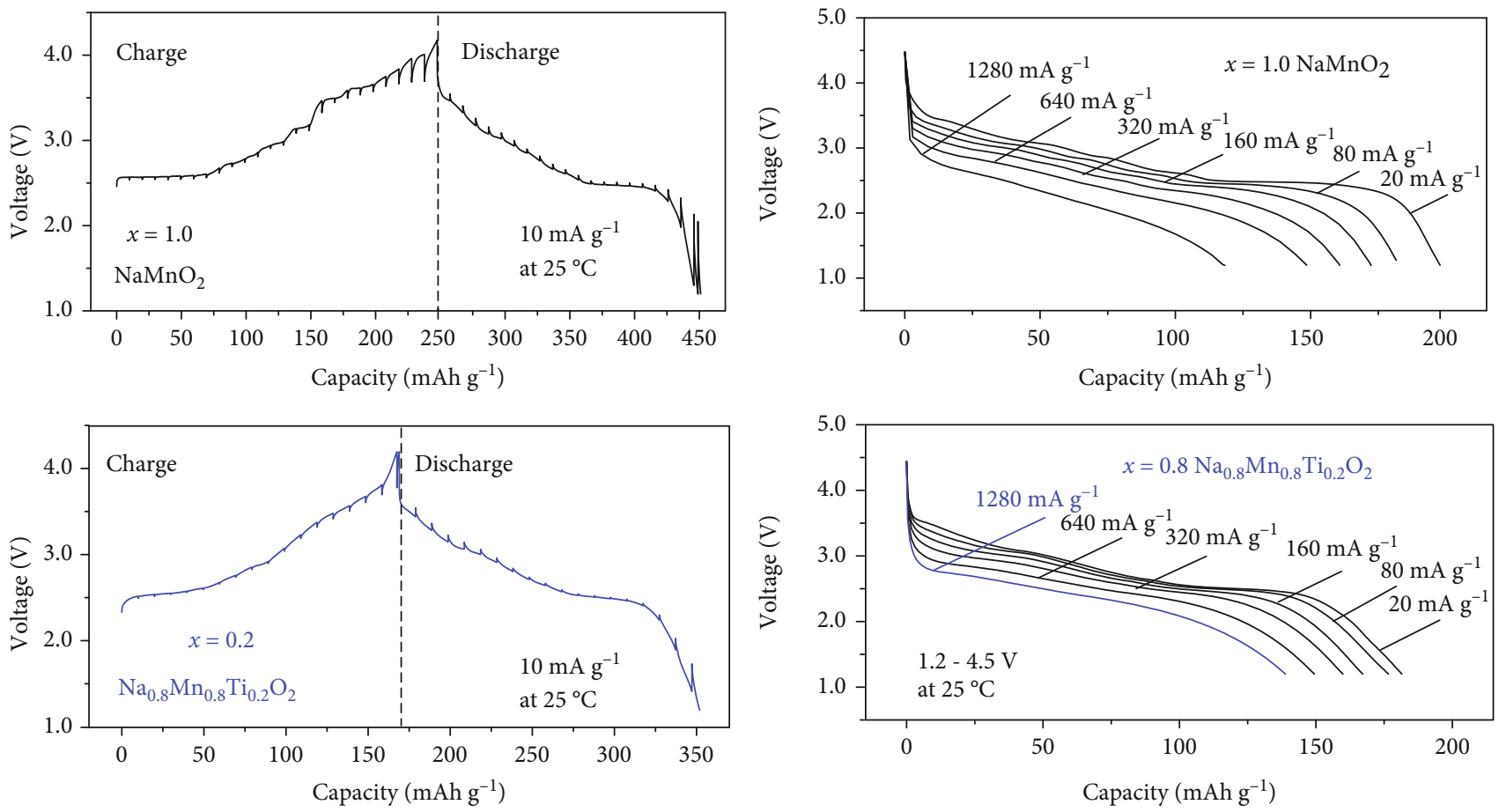

(a)

(b)

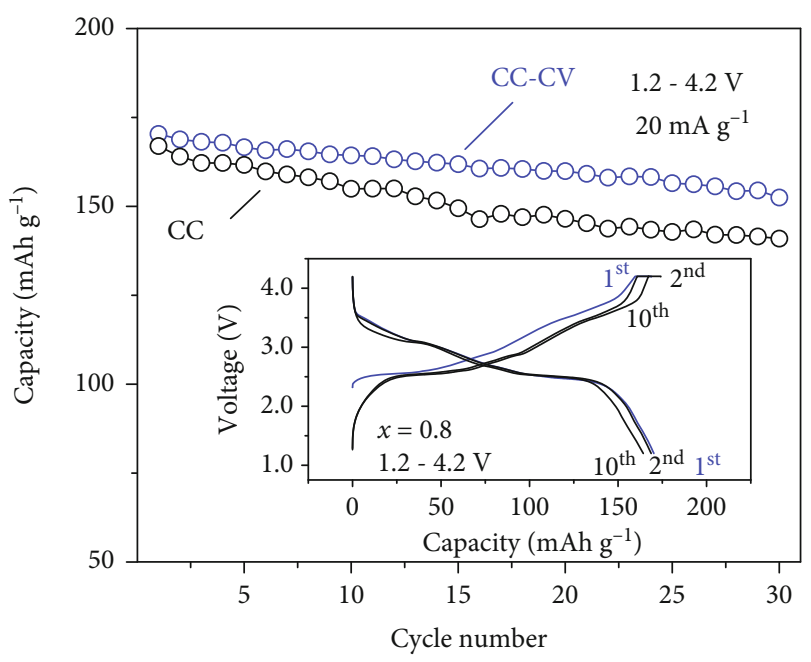

(c)

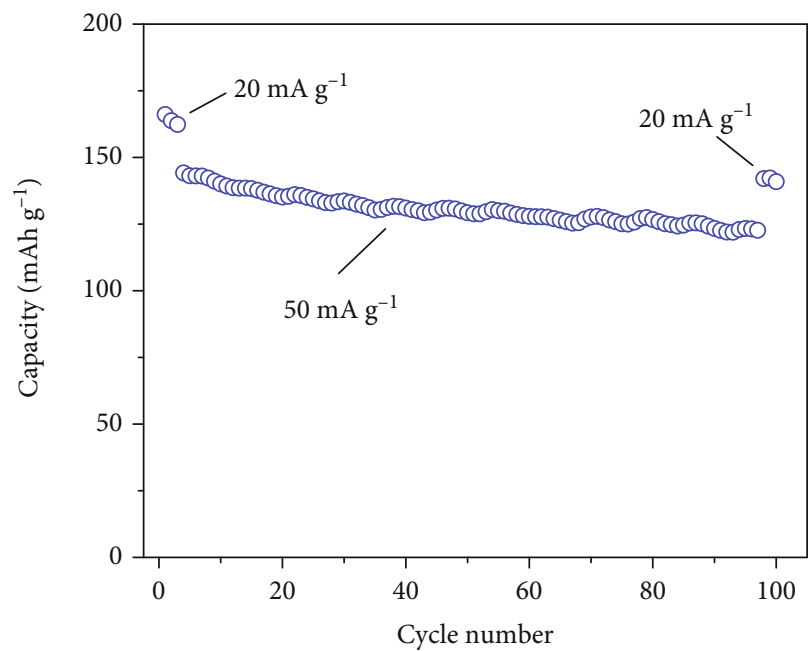

(d)

FIGURE 4: (a) Quasi-open-circuit voltage curves of the samples of (a) $x=1.0$ and 0.8 at the initial cycle. Rate capability of the samples is also shown in (b); sample loading, $4.38 \mathrm{mg} \mathrm{cm}^{-2}$ for $x=1.0$ and $4.66 \mathrm{mg} \mathrm{cm}^{-2}$ for $x=0.8$. (c) Capacity retention of the sample of $x=0.8 \mathrm{measured}$ with/without constant voltage (CV) holding at $4.2 \mathrm{~V}$ for $2 \mathrm{~h}$ after being charged at a constant current (CC) of $4.2 \mathrm{~V}$. Charge/discharge curves of the sample with voltage holding are shown in the inset. (d) An accelerated cycle test at a rate of $50 \mathrm{~mA} \mathrm{~g}^{-1}$. CV holding at $4.2 \mathrm{~V}$ for $30 \mathrm{~min}$ was applied on charge. Initial and last 3 cycles were cycled at a rate of $20 \mathrm{~mA} \mathrm{~g}^{-1}$.

with the presence of a Jahn-Teller active $\mathrm{Mn}^{3+}$ ion with a high-spin configuration is clearly different from the $\mathrm{O}^{\prime} 3 \mathrm{I}$ and II phases as illustrated in Figure 6. In addition, the interlayer distance is expanded to $5.66 \AA$. Another biphasic reaction proceeds for both $\mathrm{O}^{\prime} 3 \mathrm{II}$ and III phases in the range of $0.68 \leq y<0.58$. Crystallographic parameters of the $\mathrm{O}^{\prime} 3 \mathrm{III}$ phase are close to those of $\mathrm{Na}_{5 / 8} \mathrm{MnO}_{2}$ reported in literature [44]. Less in-plane distortion of the crystal lattice for the $\mathrm{O}^{\prime} 3$
III phase originates from the fact that the Jahn-Teller active ion in the structure is diluted on charge. On further oxidation, a single-phase reaction proceeds and the in-plane local distortion is relieved. The ratio of $a / b$ values is calculated to be $1.732(=\sqrt{ } 3)$, indicating that its symmetry has been changed from the monoclinic to rhombohedral symmetry. The 20-2 and 111 diffraction lines for the $\mathrm{O}^{\prime} 3$ III phase are merged into a single diffraction line, which is assigned to 

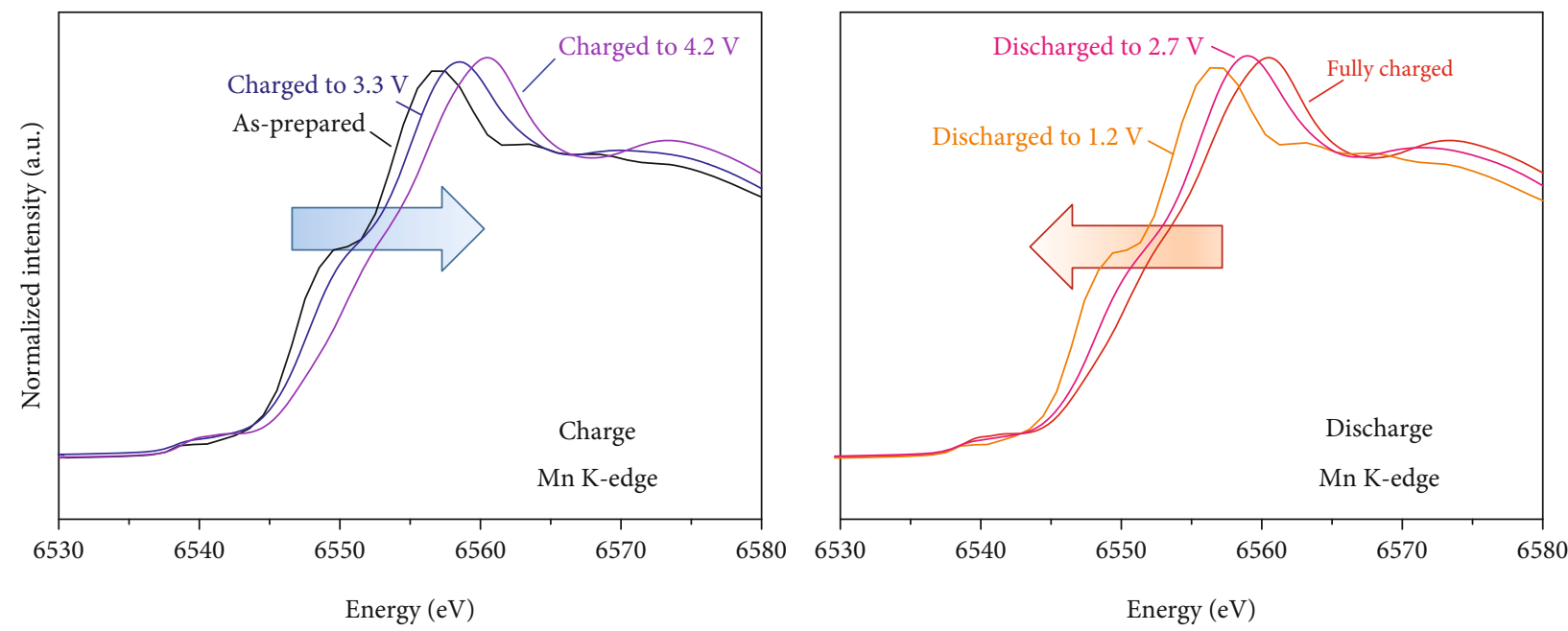

(a)

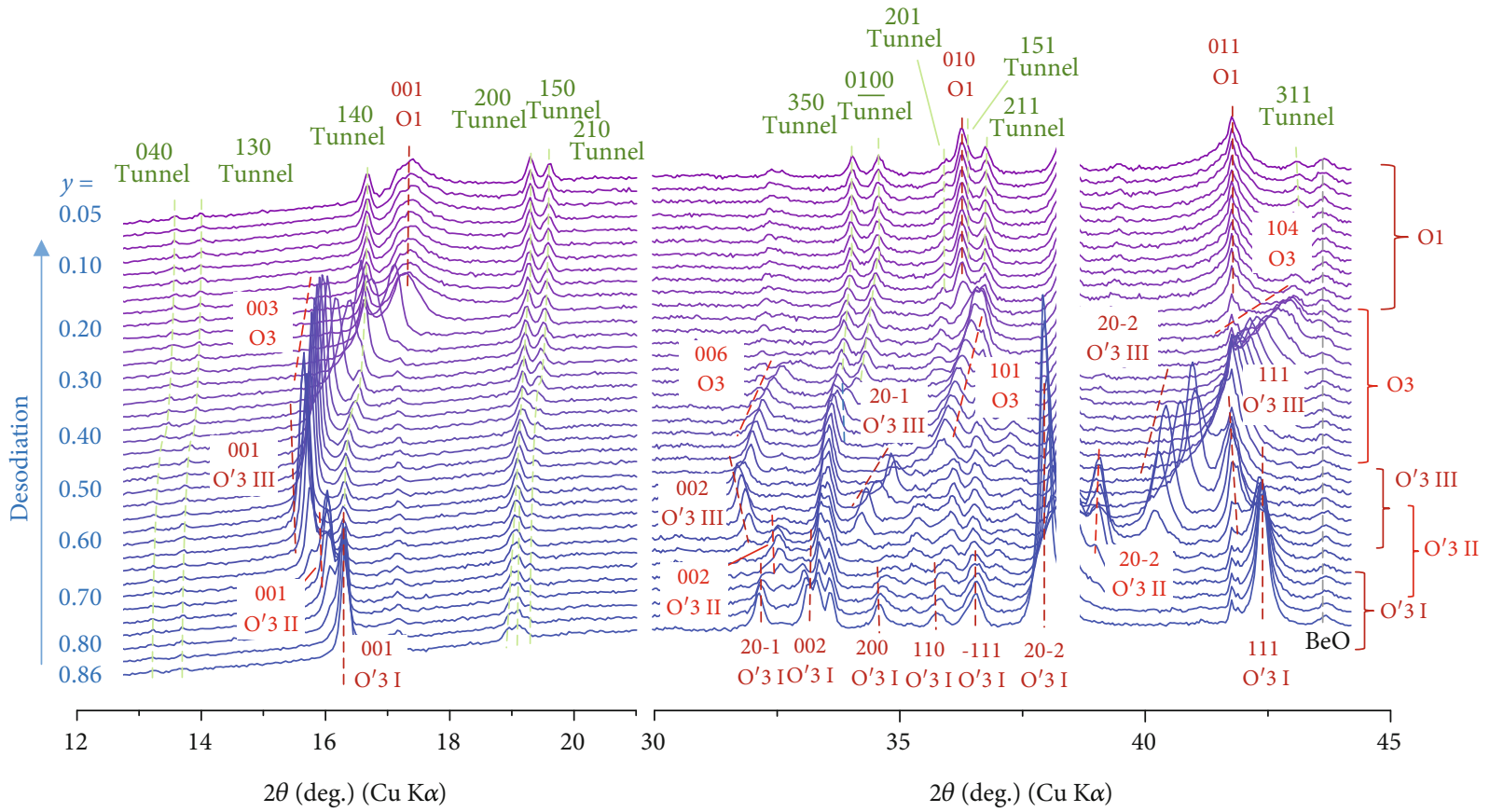

(b)

FIgURE 5: (a) Changes in XANES spectra of the sample of $x=0.8$ on charge/discharge processes and (b) in situ XRD patterns of the sample $x=0.8$ for the second charge process at $5 \mathrm{~mA} \mathrm{~g}^{-1}$. The cell was discharged to $1.2 \mathrm{~V}$ at $5 \mathrm{~mA} \mathrm{~g}^{-1}$ and then charged to $4.4 \mathrm{~V}$. Each XRD data has been collected for $1 \mathrm{~h}$ on charge.

the 104 diffraction line for an O3 phase without in-plane distortion. The single-phase $\mathrm{O} 3$ layered structure is found for the range of $0.54 \leq y \leq 0.22$ in $\mathrm{Na}_{y} \mathrm{Mn}_{0.8} \mathrm{Ti}_{0.2} \mathrm{O}_{2}$. Note that the formation of the $\mathrm{O} 1$ phase (a sequence of $\mathrm{ABAB}$ for oxygen stacking) is found after being fully charged $(y<0.22)$, which is clearly evidenced from the disappearance of the 104 line for the $\mathrm{O} 3$ phase and appearance of a new peak at 42 degrees. This peak is assigned as the 011 line for the $\mathrm{O} 1$ phase. The interlayer distance is also reduced from $5.66 \AA$, which is the maximum value on phase transition processes, to $5.13 \AA$ for the fully desodiated sample. A similar interlayer distance is observed for the $\mathrm{O} 1$ phase
(5.08 $\AA$ ) derived from stoichiometric $\mathrm{NaMnO}_{2}$ without $\mathrm{Ti}$ substitution [45]. Broad diffraction lines observed for the O1 phase suggest the presence of stacking faults along the $c$-axis direction. For other $\mathrm{O} 3$ phases, e.g., $\mathrm{Na}_{y} \mathrm{Ni}_{1 / 3}$ $\mathrm{Fe}_{1 / 3} \mathrm{Mn}_{1 / 3} \mathrm{O}_{2}$ [46] and $\mathrm{Na}_{y} \mathrm{Ti}_{0.25} \mathrm{Fe}_{0.25} \mathrm{Co}_{0.25} \mathrm{Ni}_{0.25} \mathrm{O}_{2}$ [47], the formation of an OP2 phase (a sequence of ABCA), which contains alternating octahedral and prismatic sites for sodium ion layers, is evidenced. This phase is regarded as the intergrown layered material of P3- and O1-type structures. The interlayer distance of $y=\sim 0$ in $\mathrm{Na}_{y} \mathrm{Ni}_{1 / 3}$ $\mathrm{Fe}_{1 / 3} \mathrm{Mn}_{1 / 3} \mathrm{O}_{2}$ is observed to be $5.05 \AA$ [46], and this value is also close to that of $\mathrm{Na}_{0.05} \mathrm{Mn}_{0.8} \mathrm{Ti}_{0.2} \mathrm{O}_{2}$. 


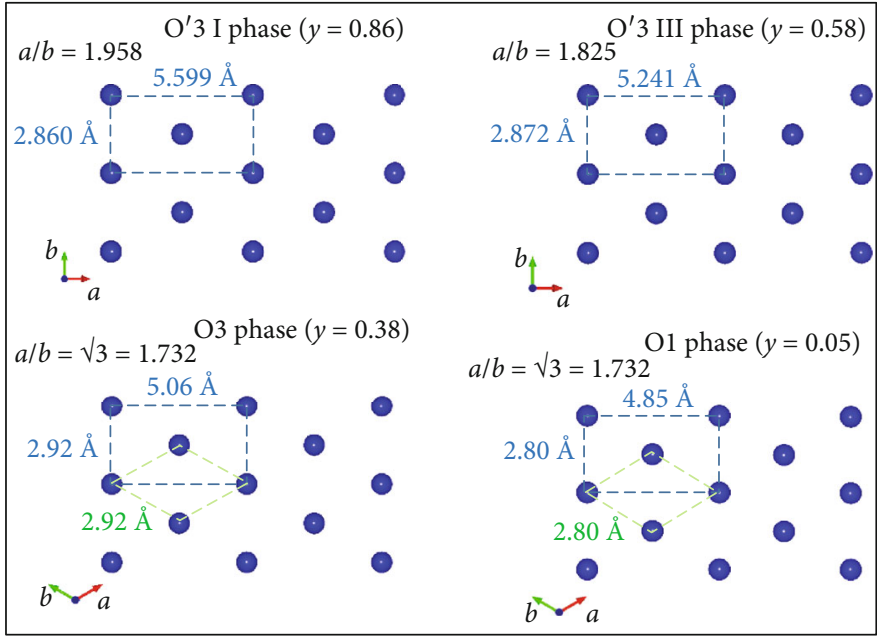

(a)

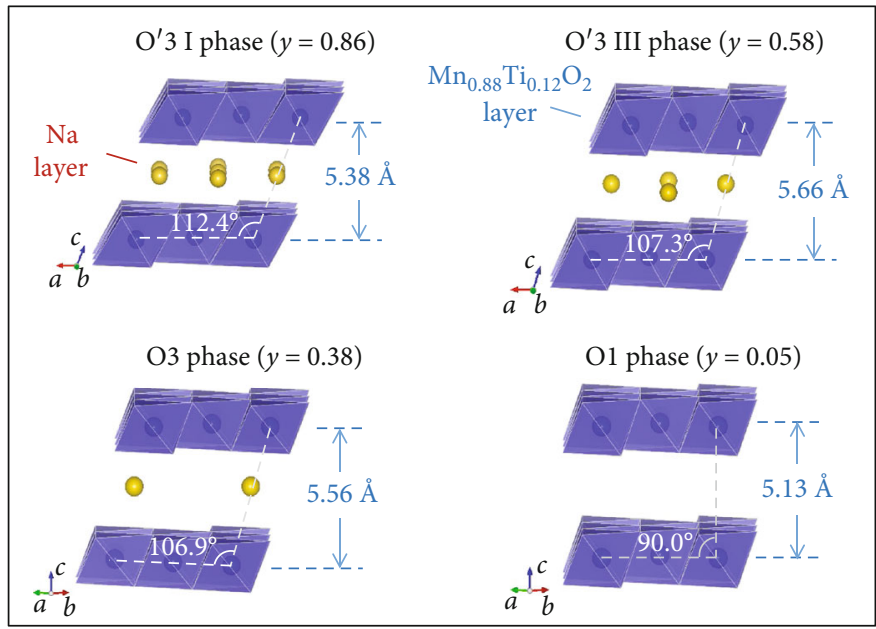

(b)

FIGURE 6: Summary of phase transition processes for $\mathrm{Na}_{y} \mathrm{Mn}_{0.88} \mathrm{Ti}_{0.12} \mathrm{O}_{2}$ with the layered structure: (a) in-plane cation arrangements and (b) stacking of the $\mathrm{Mn}_{0.88} \mathrm{Ti}_{0.12} \mathrm{O}_{2}$ slabs along the $c$-axis direction.

Note that phase transition processes simultaneously occur for the minor phase, $\mathrm{Na}_{4} \mathrm{Mn}_{4} \mathrm{Ti}_{5} \mathrm{O}_{18}$, with the tunneltype structure. The continuous contraction of the crystal lattice and shift of diffraction lines to the higher diffraction angle are observed on charge, which is consistent with the trend reported in literature [39]. Relatively clear phase transition is noted in the range of $0.38<y<0.28$ in $\mathrm{Na}_{y} \mathrm{Mn}_{0.8-}$ $\mathrm{Ti}_{0.2} \mathrm{O}_{2}$. For instance, the 140 diffraction line at 16.0 degrees shifts to 16.5 degrees as shown in Figure 5(b) on charge. A peak intensity of 140 and 200 is increased on charge, and a similar observation is also noted for $\mathrm{Na}_{y} \mathrm{Mn}_{4} \mathrm{Ti}_{5} \mathrm{O}_{18}$ [39]. Less lattice distortion is expected for the charged sample with diluted Jahn-Teller active $\mathrm{Mn}^{3+}$ ions. These phase transition competes with the formation of the major O3 phase. Continuous shift of diffraction lines is observed in the entire region, but the unit cell volume change is less pronounced for the tunnel phase when compared with the layered phase. Because the tunnel and layered phases are uniformly dispersed as shown in Supporting Figure S1, the strain induced by large volume change of the layered phase would be partly relieved by the presence of the tunnel phase with less volume change around the layered phase. Structural changes of the samples with/without Ti ions after 10 cycles were also examined. Crystallinity of the sample is clearly reduced for the nonsubstituted sample (Supporting Figure S5), indicating that strains are induced after electrochemical cycles. The dissolution of $\mathrm{Mn}$ ions from the crystal lattice of $\mathrm{NaMnO}_{2}$ may result in the broadening of diffraction lines. Although the phase-pure sample is not obtained in the binary system of $\mathrm{NaMnO}_{2}-\mathrm{TiO}_{2}$, both layered and tunnel phases are electrochemically active as clearly shown in Figure 5(b). Therefore, no sacrifice of reversible capacity is observed for these nonpure phases, which are used as highcapacity positive electrode materials for high-performance and cost-effective sodium storage applications combined with carbonaceous negative electrode materials [48] in the future.

\section{Conclusions}

The influence of the Ti substitution on the structural and electrochemical properties of $\mathrm{NaMnO}_{2}$ has been examined 
in this study. A combined study of neutron and synchrotron $\mathrm{X}$-ray diffraction reveals partial substitution of Ti ions and the formation of layered $\mathrm{Na}_{1-x} \mathrm{Mn}_{1-x} \mathrm{Ti}_{x} \mathrm{O}_{2}$ with tunnel-type $\mathrm{Na}_{4} \mathrm{Mn}_{4} \mathrm{Ti}_{5} \mathrm{O}_{18}$ as the minor phase. The Ti-substituted sample has higher chemical stability, and thus, dissolution of $\mathrm{Mn}$ ions into electrolyte on electrochemical cycles is suppressed, leading to good cyclability and rate capability as the electrode material. An in situ XRD study on $\mathrm{Na}_{y} \mathrm{Mn}_{0.8-}$ $\mathrm{Ti}_{0.2} \mathrm{O}_{2}$ reveals that the partial suppression of unit cell volume change is also evidenced compared with stoichiometric and nonsubstituted $\mathrm{NaMnO}_{2}$. Moreover, both layered and tunnel-type oxides are electrochemically active, and simultaneous phase transitions are observed on sodiation/desodiation processes. High reversibility as the electrode material also originates from $\mathrm{Mn}^{3+} / \mathrm{Mn}^{4+}$ cationic redox as proofed by XAS measurement. The optimization of synthesis conditions, chemical compositions, and particle morphology would result in further improvement of electrode performance, contributing to the development of cost-effective $\mathrm{Na}$-based battery system without less abundant elements.

\section{Data Availability}

All data presented in the paper and the supporting information are available from the corresponding author upon reasonable request.

\section{Ethical Approval}

The synchrotron radiation experiments were performed at the BL19B2 of SPring-8 with the approval of the Japan Synchrotron Radiation Research Institute (JASRI) (Proposal 2019B1685). The neutron scattering experiment was approved by the Neutron Scattering Program Advisory Committee of IMSS, KEK (Proposal No. 2019S10). The synchrotron X-ray absorption work was done under the approval of the Photon Factory Program Advisory Committee (Proposal No. 2019G033).

\section{Conflicts of Interest}

The authors declare that they have no conflicts of interest.

\section{Acknowledgments}

NY acknowledges the partial support from Japan Society for the Promotion of Science (JSPS), Grant-in-Aid for Scientific Research (Grant Numbers 15H05701, 18H02076, and 19H05816), and MEXT program "Elements Strategy Initiative to Form Core Research Center (JPMXP0112101003)," Ministry of Education, Culture, Sports, Science and Technology, Japan.

\section{Supplementary Materials}

Table S1: refined structural parameters obtained from the synchrotron XRD pattern of the sample of $x=0.8$ by the Rietveld method. Table S2: refined structural parameters obtained from the ND pattern of the sample of $x=0.8$ by the Rietveld method. Figure S1: SEM/EDX maps of the sam- ple of $x=0.8$. Phase segregation is clearly evidenced. Figure S2: charge/discharge curves and quasi-open-circuit voltage of "as-prepared" $\mathrm{NaMnO}_{2}$. Figure S3: Nyquist plots of the samples of $x=1.0$ and 0.8 after being charged to a capacity of $150 \mathrm{~mA} \mathrm{~h}^{-1}$. Figure S4: charge/discharge curves of the sample of $x=0.8$ in the range of 1.5 and $4.2 \mathrm{~V}$ without voltage holding at $4.2 \mathrm{~V}$. Figure S5: XRD patterns of composite electrodes of the samples $(x=1.0$ and 0.8$)$; as-prepared electrodes and electrodes after 10 cycles in $\mathrm{Na}$ cells. (Supplementary Materials)

\section{References}

[1] H. Kim, H. Kim, Z. Ding et al., "Recent progress in electrode materials for sodium-ion batteries," Advanced Energy Materials, vol. 6, no. 19, pp. 1-38, 2016.

[2] N. Yabuuchi, K. Kubota, M. Dahbi, and S. Komaba, "Research development on sodium-ion batteries," Chemical Reviews, vol. 114, no. 23, pp. 11636-11682, 2014.

[3] P. Barpanda, G. Liu, C. D. Ling et al., " $\mathrm{Na}_{2} \mathrm{FeP}_{2} \mathrm{O}_{7}$ : a safe cathode for rechargeable sodium-ion batteries," Chemistry of Materials, vol. 25, no. 17, pp. 3480-3487, 2013.

[4] P. Barpanda, G. Oyama, S. I. Nishimura, S. C. Chung, and A. Yamada, "A 3.8-V earth-abundant sodium battery electrode," Nature Communications, vol. 5, no. 1, 2014.

[5] X. Ma, H. Chen, and G. Ceder, "Electrochemical properties of monoclinic $\mathrm{NaMnO}_{2}$," Journal of the Electrochemical Society, vol. 158, no. 12, article A1307, 2011.

[6] N. Yabuuchi, M. Kajiyama, J. Iwatate et al., "P2-type $\mathrm{Na}_{\mathrm{x}}\left[\mathrm{Fe}_{1 / 2} \mathrm{Mn}_{1 / 2}\right] \mathrm{O}_{2}$ made from earth-abundant elements for rechargeable Na batteries," Nature Materials, vol. 11, no. 6, pp. 512-517, 2012.

[7] J. Zhao, L. Zhao, N. Dimov, S. Okada, and T. Nishida, "Electrochemical and thermal properties of $\alpha-\mathrm{NaFeO}_{2}$ cathode for $\mathrm{Na}$ ion batteries," Journal of the Electrochemical Society, vol. 160, no. 5, pp. A3077-A3081, 2013.

[8] W. Zhao, H. Kirie, A. Tanaka, M. Unno, S. Yamamoto, and H. Noguchi, "Synthesis of metal ion substituted P2$\mathrm{Na}_{2 / 3} \mathrm{Ni}_{1 / 3} \mathrm{Mn}_{2 / 3} \mathrm{O}_{2}$ cathode material with enhanced performance for $\mathrm{Na}$ ion batteries," Materials Letters, vol. 135, pp. 131-134, 2014.

[9] J. S. Thorne, R. A. Dunlap, and M. N. Obrovac, "Investigation of $\mathrm{P} 2-\mathrm{Na}_{2 / 3} \mathrm{Mn}_{1 / 3} \mathrm{Fe}_{1 / 3} \mathrm{Co}_{1 / 3} \mathrm{O}_{2}$ for $\mathrm{Na}$-ion battery positive electrodes," Journal of the Electrochemical Society, vol. 161, no. 14, pp. A2232-A2236, 2014.

[10] N. Yabuuchi, R. Hara, K. Kubota, J. Paulsen, S. Kumakura, and S. Komaba, "A new electrode material for rechargeable sodium batteries: P2-type $\mathrm{Na}_{2 / 3}\left[\mathrm{Mg}_{0.28} \mathrm{Mn}_{0.72}\right] \mathrm{O}_{2}$ with anomalously high reversible capacity," Journal of Materials Chemistry A, vol. 2, no. 40, pp. 16851-16855, 2014.

[11] Y. Ono, "Structural analysis of $\mathrm{NaCuO}_{2}$ cathode at various charged/discharged stages and its reaction mechanism," Electrochemistry, vol. 86, no. 6, pp. 309-314, 2018.

[12] X. Cao, X. Li, Y. Qiao et al., "Restraining oxygen loss and suppressing structural distortion in a newly Ti-substituted layered oxide $\mathrm{P} 2-\mathrm{Na}_{0.66} \mathrm{Li}_{0.22} \mathrm{Ti}_{0.15} \mathrm{Mn}_{0.63} \mathrm{O}_{2}$," ACS Energy Letters, vol. 4, no. 10, pp. 2409-2417, 2019.

[13] T. Risthaus, L. Chen, J. Wang et al., "P3 $\mathrm{Na}_{0.9} \mathrm{Ni}_{0.5} \mathrm{Mn}_{0.5} \mathrm{O}_{2}$ Cathode material for sodium ion batteries," Chemistry of Materials, vol. 31, no. 15, pp. 5376-5383, 2019. 
[14] N. Yabuuchi and S. Komaba, "Recent research progress on iron- and manganese-based positive electrode materials for rechargeable sodium batteries," Science and Technology of Advanced Materials, vol. 15, no. 4, article 043501, 2014.

[15] H. Kim, D. J. Kim, D.-H. Seo et al., "Ab initio study of the sodium intercalation and intermediate phases in $\mathrm{Na}_{0.44} \mathrm{MnO}_{2}$ for sodium-ion battery," Chemistry of Materials, vol. 24, no. 6, pp. 1205-1211, 2012.

[16] S. Kumakura, Y. Tahara, K. Kubota, K. Chihara, and S. Komaba, "Sodium and manganese stoichiometry of P2type $\mathrm{Na}_{2 / 3} \mathrm{MnO}_{2}$," Angewandte Chemie, vol. 55, no. 41, pp. 12760-12763, 2016.

[17] C. Delmas, C. Fouassier, and P. Hagenmuller, "Structural classification and properties of the layered oxides," Physica $B$ \& $C$, vol. 99, no. 1-4, pp. 81-85, 1980.

[18] M. Sathiya, J. Thomas, D. Batuk, V. Pimenta, R. Gopalan, and J. M. Tarascon, "Dual stabilization and sacrificial effect of $\mathrm{Na}_{2} \mathrm{CO}_{3}$ for increasing capacities of $\mathrm{Na}$-ion cells based on $\mathrm{P} 2-\mathrm{Na}_{\mathrm{x}} \mathrm{MO}_{2}$ electrodes," Chemistry of Materials, vol. 29, no. 14, pp. 5948-5956, 2017.

[19] T. Kobayashi, W. Zhao, H. B. Rajendra, K. Yamanaka, T. Ohta, and N. Yabuuchi, "Nanosize cation-disordered rocksalt oxides: $\mathrm{Na}_{2} \mathrm{TiO}_{3}-\mathrm{NaMnO}_{2}$ binary system," Small, vol. 15, article 1902462, 2019.

[20] A. Mendiboure, C. Delmas, and P. Hagenmuller, "Electrochemical intercalation and deintercalation of $\mathrm{Na}_{\mathrm{x}} \mathrm{MnO}_{2}$ bronzes," Journal of Solid State Chemistry, vol. 57, no. 3, pp. 323-331, 1985.

[21] J. Billaud, R. J. Clément, A. R. Armstrong et al., “ $\beta-\mathrm{NaMnO}_{2}$ : a high-performance cathode for sodium-ion batteries," Journal of the American Chemical Society, vol. 136, no. 49, pp. 17243-17248, 2014.

[22] A. M. Abakumov, A. A. Tsirlin, I. Bakaimi, G. Van Tendeloo, and A. Lappas, "Multiple twinning as a structure directing mechanism in layered rock-salt-type oxides: $\mathrm{NaMnO}_{2}$ polymorphism, redox potentials, and magnetism," Chemistry of Materials, vol. 26, no. 10, pp. 3306-3315, 2014.

[23] L.-W. Jiang, Y. X. Lu, Y. S. Wang et al., “A high-temperature $\beta$ phase $\mathrm{NaMnO}_{2}$ stabilized by $\mathrm{Cu}$ doping and its $\mathrm{Na}$ storage properties," Chinese Physics Letters, vol. 35, no. 4, article 048801, 2018.

[24] M. Shishkin, S. Kumakura, S. Sato, K. Kubota, S. Komaba, and H. Sato, "Unraveling the role of doping in selective stabilization of $\mathrm{NaMnO}_{2}$ polymorphs: combined theoretical and experimental study," Chemistry of Materials, vol. 30, no. 4, pp. 1257-1264, 2018.

[25] Y. Tsuchiya, K. Takanashi, T. Nishinobo et al., "Layered $\mathrm{Na}_{\mathrm{x}} \mathrm{Cr}_{\mathrm{x}} \mathrm{Ti}_{1-\mathrm{x}} \mathrm{O}_{2}$ as bifunctional electrode materials for rechargeable sodium batteries," Chemistry of Materials, vol. 28, no. 19, pp. 7006-7016, 2016.

[26] W. Mumme, "The structure of $\mathrm{Na}_{4} \mathrm{Mn}_{4} \mathrm{Ti}_{5} \mathrm{O}_{18}$," Acta Crystallographica. Section B, vol. 24 , no. 8, pp. 1114-1120, 1968.

[27] K. Osaka, Y. Yokozawa, Y. Torizuka et al., "Versatile highthroughput diffractometer for industrial use at BL19B2 in SPring-8," AIP Conference Proceedings, vol. 2054, article 050008, 2019.

[28] F. Izumi and K. Momma, "Three-dimensional visualization in powder diffraction," Solid State Phenomena, vol. 130, pp. 1520, 2007.
[29] M. Yonemura, K. Mori, T. Kamiyama et al., "Development of SPICA, new dedicated neutron powder diffractometer for battery studies," Journal of Physics Conference Series, vol. 502, article 012053, 2014.

[30] R. Oishi, M. Yonemura, Y. Nishimaki et al., "Rietveld analysis software for J-PARC," Nuclear Instruments and Methods in Physics Research Section A: Accelerators, Spectrometers, Detectors and Associated Equipment, vol. 600, no. 1, pp. 94-96, 2009.

[31] R. Oishi-Tomiyasu, M. Yonemura, T. Morishima et al., "Application of matrix decomposition algorithms for singular matrices to the Pawley method in Z-Rietveld," Journal of Applied Crystallography, vol. 45, no. 2, pp. 299-308, 2012.

[32] M. Newville, "IFEFFIT: interactive XAFS analysis and FEFF fitting," Journal of Synchrotron Radiation, vol. 8, no. 2, pp. 322-324, 2001.

[33] X. Jiang, S. Liu, H. Xu, L. Chen, J. Yang, and Y. Qian, "Tunnelstructured $\mathrm{Na}_{0.54} \mathrm{Mn}_{0.50} \mathrm{Ti}_{0.51} \mathrm{O}_{2}$ and $\mathrm{Na}_{0.54} \mathrm{Mn}_{0.50} \mathrm{Ti}_{0.51} \mathrm{O}_{2} / \mathrm{C}$ nanorods as advanced cathode materials for sodium-ion batteries," Chemical Communications, vol. 51, no. 40, pp. 8480 8483, 2015.

[34] M. Jayakumar, K. Hemalatha, K. Ramesha, and A. S. Prakash, "Framework structured $\mathrm{Na}_{4} \mathrm{Mn}_{4} \mathrm{Ti}_{5} \mathrm{O}_{18}$ as an electrode for Naion storage hybrid devices," Physical Chemistry Chemical Physics, vol. 17, no. 32, pp. 20733-20740, 2015.

[35] X. Gao, J. Chen, H. Liu et al., "Copper-substituted $\mathrm{Na}_{\mathrm{x}} \mathrm{MO}_{2}$ $(\mathrm{M}=\mathrm{Fe}, \mathrm{Mn})$ cathodes for sodium ion batteries: enhanced cycling stability through suppression of Mn(III) formation," Chemical Engineering Journal, vol. 406, article 126830, 2021.

[36] N. Yabuuchi, R. Hara, M. Kajiyama et al., "New $\mathrm{O}_{2} / \mathrm{P} 2$-type Li-excess layered manganese oxides as promising multifunctional electrode materials for rechargeable $\mathrm{Li} / \mathrm{Na}$ batteries," Advanced Energy Materials, vol. 4, no. 13, article 1301453, 2014.

[37] Z. Zhu, H. Peelaers, and C. G. Van de Walle, "Hydrogeninduced degradation of $\mathrm{NaMnO}_{2}$," Chemistry of Materials, vol. 31, no. 14, pp. 5224-5228, 2019.

[38] M. D. Radin and A. Van der Ven, "Simulating charge, spin, and orbital ordering: application to Jahn-Teller distortions in layered transition-metal oxides," Chemistry of Materials, vol. 30, no. 3, pp. 607-618, 2018.

[39] Y. Wang, J. Liu, B. Lee et al., “Ti-substituted tunnel-type $\mathrm{Na}_{0.44} \mathrm{MnO}_{2}$ oxide as a negative electrode for aqueous sodium-ion batteries," Nature Communications, vol. 6, no. 1, article 6401, 2015.

[40] N. Takeda, I. Ikeuchi, R. Natsui, K. Nakura, and N. Yabuuchi, "Improved electrode performance of lithium-excess molybdenum oxyfluoride: titanium substitution with concentrated electrolyte," ACS Applied Energy Materials, vol. 2, no. 3, pp. 1629-1633, 2019.

[41] Y. Kobayashi, M. Sawamura, S. Kondo et al., "Activation and stabilization mechanisms of anionic redox for Li storage applications: joint experimental and theoretical study on $\mathrm{Li}_{2} \mathrm{TiO}_{3}-$ $\mathrm{LiMnO}_{2}$ binary system," Materials Today, vol. 37, pp. 43-55, 2020.

[42] T. Kobayashi, W. Zhao, H. B. Rajendra, K. Yamanaka, T. Ohta, and N. Yabuuchi, "Nanosize cation-disordered rocksalt oxides: $\mathrm{Na}_{2} \mathrm{TiO}_{3}-\mathrm{NaMnO}_{2}$ binary system," Small, vol. 16, no. 12, article 1902462, 2020.

[43] M. Sawamura, S. Kobayakawa, J. Kikkawa et al., "Nanostructured $\mathrm{LiMnO}_{2}$ with $\mathrm{Li}_{3} \mathrm{PO}_{4}$ integrated at the atomic scale for 
high-energy electrode materials with reversible anionic redox," ACS Central Science, vol. 6, no. 12, pp. 2326-2338, 2020.

[44] X. Li, X. Ma, D. Su et al., "Direct visualization of the JahnTeller effect coupled to $\mathrm{Na}$ ordering in $\mathrm{Na}_{5 / 8} \mathrm{MnO}_{2}$," Nature Materials, vol. 13, no. 6, pp. 586-592, 2014.

[45] X. Chen, Y. Wang, K. Wiaderek et al., "Super charge separation and high voltage phase in $\mathrm{Na}_{\mathrm{x}} \mathrm{MnO}_{2}$," Advanced Functional Materials, vol. 28, no. 50, article 1805105, 2018.

[46] M. Jeong, H. Lee, J. Yoon, and W.-S. Yoon, "O ${ }_{3}$-type $\mathrm{NaNi}_{1 / 3} \mathrm{Fe}_{1 / 3} \mathrm{Mn}_{1 / 3} \mathrm{O}_{2}$ layered cathode for $\mathrm{Na}$-ion batteries: structural evolution and redox mechanism upon $\mathrm{Na}$ (de) intercalation," Journal of Power Sources, vol. 439, article 227064, 2019.

[47] J. C. Kim, D. H. Kwon, J. H. Yang et al., "Direct observation of alternating octahedral and prismatic sodium layers in $\mathrm{O}_{3}$-type transition metal oxides," Advanced Energy Materials, vol. 10, no. 31, article 2001151, 2020.

[48] S. Shimizu, H. B. Rajendra, R. Watanuki, and N. Yabuuchi, "Li/Na storage properties of disordered carbons synthesized by mechanical milling," Electrochemistry, vol. 87, no. 5, pp. 276-280, 2019.

[49] K. Momma and F. Izumi, "VESTA 3for three-dimensional visualization of crystal, volumetric and morphology data," Journal of Applied Crystallography, vol. 44, no. 6, pp. 12721276, 2011. 